\title{
BIOCHEMICAL EFFECTS OF OLEUROPEIN IN STREPTOZOTOCIN INDUCED DIABETIC MALE RAT
}

\author{
Sina Amirnahavandirahbar, Mohammad Reza Nasirzadeh \\ Physiology Department, Faculty of Veterinary Medicine, Tabriz Branch, \\ Islamic Azad University, Tabriz, Iran
}

Received 4 October 2017; Received in revised form 6 May 2018; Accepted 25 May 2018

\begin{abstract}
Diabetes is a chronic disease characterized by a disorder in the metabolism of proteins, fats, and carbohydrates. The liver as a non-insulin dependent organ plays an important role in the regulation of blood fat and glucose. Most blood glucose lowering drugs that are introduced for treatment have side effects in long-term consumption. Therefore, to control diabetes and its complications, the use of herbal drugs is widely considered nowadays. The present study investigates the biochemical effects of oleuropein in diabetic male rats. In this study, 30 adult male Wistar rats with a weight range of $190 \pm 30$ gr were equally divided into 3 groups randomly: 1) control group or intact animals, 2) diabetic animals, and 3) treatment group, which received $60 \mathrm{mg} / \mathrm{kg}$ oleuropein for 30 days by gastric gavage. Diabetes was induced in diabetic and treatment groups by injection of streptozotocin $(60 \mathrm{mg} / \mathrm{kg})$ intraperitoneally. At the end of the treatment, the levels of triglyceride, cholesterol, LDL, HDL, VLDL, blood glucose, HbA1C, and activity of AST and ALT were determined. The results showed that the serum lipid profile and blood glucose increased significantly in the diabetic group compared with the control group ( $\mathrm{p}<0.05)$. Also, $\mathrm{HbA1C}$ and atherogenic index decreased significantly in the treatment group compared with the diabetic group ( $<<0.05)$. This study showed that oral administration of oleuropein has hypoglycemic effects, which can reduce the serum levels of the lipids profile and the atherogenic index in streptozotocin-induced diabetic male rats.
\end{abstract}

Key words: oleuropein, serum lipid profile, diabetes, liver enzymes, rat

\section{INTRODUCTION}

Diabetes is an endocrine disorder resulting from defects in insulin secretion or decrease in insulin sensitivity of the body or both. This disease is one of the main causes of death in advanced countries (1). Although genetic factors, obesity, and sedentary lifestyle have an important role in diabetes, the main causes of diabetes are still unknown (1). An increase in oxidative stress and change in the level of antioxidants play an important role in the pathogenesis of diabetes (2).

Corresponding author: Assist. Prof. Mohammad Reza Nasirzadeh, DVM E-mail address: mr.nasirzadeh@iaut.ac.ir

Present address: Physiology Department, Faculty of Veterinary

Medicine, Islamic Azad University, Tabriz, Iran

Phone: $+04136372274-09141015108$, Fax: +04136373935

Copyright: (C) 2018 Amirnahavandirahbar S. This is an open-access article published under the terms of the Creative Commons Attribution License which permits unrestricted use, distribution, and reproduction in any medium, provided the original author and source are credited. Competing Interests: The authors have declared that no competing interests exist.

Available Online First: 1 September 2018

Published on: 15 October 2018

https://doi.org/10.2478/macvetrev-2018-0021
Free radicals formation in diabetes by non-enzymatic glycation of proteins, glucose oxidation, and elevated lipid peroxidation leads to enzymes damage, cell machinery, and also increased insulin resistance due to oxidative stress. In diabetes, mitochondria are the main source of oxidative stress. During oxidative metabolism in the mitochondria, a part of the oxygen is consumed and converted to water, while the remaining is transformed to oxygen free radicals. These radicals are important reactive oxygen species that are converted to other reactive species including $\mathrm{ONOO}^{-}, \mathrm{OH}$, and $\mathrm{H}_{2} \mathrm{O}_{2}$. Insulin signaling is regulated by Reactive Oxygen Species/Reactive Nitrogen Species in two ways (ROS/RNS). On one hand, in response to insulin, ROS/RNS are produced to apply its physiological function, on the other hand ROS and RNS have negative regulation on insulin signaling, that is, to develop insulin resistance which is an important risk factor for diabetes (3). 
Production of free radicals is increased following a disorder in the carbohydrates metabolism (4). The overproduction of free radicals causes damage to biomolecules such as lipids, proteins, and DNA. The oxidative damage of these molecules gradually leads to chronic diseases such as diabetes, atherosclerosis, aging, and cancer. Diabetes affects all body parts including eyes, kidney, liver, and the nervous system (5). The liver shows a broad spectrum of disorders including fatty liver, cirrhosis, and cancer (5). Diabetes causes an increase in blood lipid and lipoprotein including triglycerides, VLDL, LDL, and a decrease in HDL. Uncontrolled diabetes can lead to diabetic complications. These factors increase medical costs and decrease the quality of life. Diabetes mellitus is one of the most important factors that widely increase the risk of coronary heart diseases with atherosclerotic origin $(6,7)$. The liver as a non-insulin dependent organ plays an important role in the regulation of blood fat and glucose. ALT and AST are the common liver enzymes that are measured to evaluate liver function. The ALT and AST are health indicators of hepatocytes (8).

Nowadays, the use of herbal drugs is increased due to their positive effect, fewer side effects, and relatively low cost. Therefore, seeking new antidiabetic alternatives from natural antioxidants has been found to be of great importance in the world (9). The presence of antioxidants such as vitamin $\mathrm{E}$ and flavonoides in diets can have protective effects in diabetic patients (10). In recent years, the study of plasma lipids and lipoprotein patterns has been considered in people with diabetes, because the abnormal level of fat leads to the development of coronary artery disease in diabetic patients (11). A decrease in insulin secretion and defect in its function cause a consequent increase in fat metabolism from adipose tissue to plasma (12). Olmez et al., in a research carried on rats fed with high-fat diet, found that the extract of olive could lower the increased level of cholesterol (13). Also, it has been recognized that a decrease in LDL concentration and increase in HDL concentration can lead to an increase in the movement of cholesterol from environmental tissues to the liver and thus facilitate catabolism and its excretion (14). The olive is abundantly used in the Mediterranean diet, it improves the risk factors for heart disease such as lipid profile, blood pressure and glucose metabolism (15). Several studies have reported that oleuropein is an antioxidant that prevents lipid oxidation and removes free radicals in vitro (16). Accordingly, it is assumed that oleuropein may be effective in dyslipidemia resulting from diabetes induced by streptozotocin in male rats.

The present study investigates effects of oleuropein on serum levels of lipid profile, liver enzymes activity, $\mathrm{HbA1C}$, and atherogenic index in the streptozotocin-induced diabetic male rat.

\section{MATERIAL AND METHODS}

\section{Animals}

This research was conducted in the Veterinary Medicine College at the Islamic Azad University, Tabriz, Iran. The protocol of this study was approved by the Ethics Committee of the Islamic Azad University of Tabriz Medical School (IR.IAU. TABRIZ.REC.1395.62).

In this study, 30 Wister male rats weighing $190 \pm 30 \mathrm{~g}$ are randomly selected and divided into three groups $(n=10)$. The rats in all three groups were kept in the same condition with free access to water and food, a temperature range of $22 \pm 2^{\circ} \mathrm{C}$, and the light cycle of light-dark 12/12 with five animals in each cage.

Group 1 (control): intact health rats, free access to water and base diet

Group 2 (diabetic): diabetic rats, received streptozotocin by a dose of $60 \mathrm{mg} / \mathrm{kg}$ intraperitoneally, free access to water and base diet (17).

Group 3 (treatment): diabetic rats, treated with oleuropein extract at a dose of $60 \mathrm{mg} / \mathrm{kg}$ per day through gavages for 30 days (18).

\section{Diabetes induction}

Diabetes was induced in the second and third groups by injection of streptozotocin $(60 \mathrm{mg} / \mathrm{kg})$ intraperitoneally. 72 hours after streptozotocin injection, blood samples were collected from the orbital sinus under general anesthesia. Blood glucose was measured by glucometer and the rats with blood glucose above $300 \mathrm{mg} / \mathrm{dL}$ were selected as diabetic (16).

At the end of the study period, the blood sample was obtained from the orbital sinus animals in all groups. Moreover, the serum level of the lipid profile, liver enzymes of the serum, and blood sugar were measured using diagnostic commercial kits.

\section{Preparation of oleuropein}

Oleuropein was prepared in the Ardebil Azad University of Medical Sciences using the premature olive (Marie canned variety). Then, using preparative HPLC it was automatically separated 
and purified. Its purity was measured using a standard oleuropein (Sigma Aldrich).

\section{Biochemical study}

The serum levels of blood sugar were measured using a glucometer (AccuaChek, USA), triglyceride and cholesterol were measured using commercial kits (Pars Azmoon, Iran). The high-density lipoprotein was measured using the commercial kit (Pars Azmoon, Iran). The low-density lipoprotein and very low-density lipoprotein were calculated according to the Friedewald equation (18), proposed by Friedewald. The serum concentration of liver enzymes of alanine, aminotransferase, and aspartate aminotransferase were measured using the commercial kit (Pars Az moon, Iran) according to the manufacturer's instruction. The serum levels of creatinine (Pars Azmoon, Iran) and urea (ZiestChem, Iran) were measured. The atherogenic index was determined by using the equation proposed by Ikewuchi and the Ikewuchi equation (16).

\section{Statistical analysis}

In this study, the obtained data were analyzed using the statistical method of one way variance analysis (ANOVA, SPSS version 22) and post-hoc Duncan test, with the significance level considered as $\mathrm{p}<0.05$.

\section{RESULTS}

At the beginning of the study, the statistical study of data related to animals' average weight showed no significant difference between animals in different groups $(\mathrm{p}>0.05)$. However at the end of the study, the weight of the diabetic animals was significantly decreased compared to the control group $(\mathrm{p}<0.05)$. Also, no significant difference was observed between the treatment and the diabetic group ( $\mathrm{p}>0.05)$.

The analysis of data related to blood's glucose showed that the Mean serum glucose concentration was significantly increased in the diabetic group compared to the control group $(\mathrm{p}<0.05)$. Also, there was a significant difference between the treatment group with diabetics and the control groups $(\mathrm{p}<0.05)$.

Comparison of mean serum concentration of triglyceride in this study showed a significant difference between the control and the diabetic groups $(\mathrm{p}<0.05)$. However, there was no significant difference between the treatment group and the diabetic group $(\mathrm{p}>0.05)$.

The comparison of the mean serum concentration of cholesterol showed no significant difference between the control group and the diabetic group. Also, it was identified that there is a significant difference between the treatment group with the diabetic and the control groups $(\mathrm{p}<0.05)$.

The statistical study of mean serum concentration of LDL and HDL in animals of the study groups showed that a significant difference between the diabetic and the control group $(\mathrm{p}<0.05)$, while there was no significant difference between the diabetic and the treatment groups $(\mathrm{p}>0.05)$.

Also, the comparison of the mean serum concentration of VLDL of animals in different groups showed that there is a significant difference between the control and the diabetic groups ( $p$ $<0.05)$. While there is not any significant difference between the control and the treatment groups ( $p$ $>0.05$ ).

The comparison of mean atherosclerosis index in different groups showed that there is a significant difference between the control group and the diabetic and treatment groups $(\mathrm{p}<0.05)$.

Table 1. Mean of body weight and serum concentration of glucose, urea and creatinin in the studied groups. The values represent the mean \pm SE for ten rats per group

\begin{tabular}{|c|c|c|c|c|c|}
\hline Parameter & Control & Diabetic & Treatment & $\mathbf{F}$ & Pvalue \\
\hline B. W. (g) before & $167.75 \pm 2.8563 \mathrm{a}$ & $173.25 \pm 1.5357 \mathrm{a}$ & $166 \pm 3.2558 \mathrm{a}$ & 0.858 & 0.448 \\
\hline B.W. (g) after & $184.25 \pm 4.2299 \mathrm{a}$ & $143.25 \pm 9.4813 b$ & $161.28 \pm 2.5801 \mathrm{ab}$ & 5.590 & 0.019 \\
\hline GLC (mg/dl) before & $87.25 \pm 1.2213 \mathrm{a}$ & $86.25 \pm 2.2565 a$ & $84.14 \pm 1.9530 \mathrm{a}$ & 0.385 & 0.688 \\
\hline GLC (mg/dl) after & $82.75 \pm 2.7371 \mathrm{c}$ & $375.75 \pm 16.3678 \mathrm{a}$ & $214.28 \pm 18.5411 b$ & 35.83 & 0.000 \\
\hline Urea (mg/dl) & $24.75 \pm 0.7012 \mathrm{c}$ & $38.50 \pm 0.8366 a$ & $31.42 \pm 1.4007 \mathrm{~b}$ & 14.78 & 0.001 \\
\hline Creatinine (mg/dl) & $1.5 \pm 0.0999 \mathrm{a}$ & $2.05 \pm 0.1169 \mathrm{a}$ & $1.82 \pm 0.0746 \mathrm{a}$ & 3.53 & 0.062 \\
\hline
\end{tabular}

Different letters in each row indicate a significant difference between groups. Significance level was considered as $\mathrm{P}<0.05$. B.Wafter: ${ }^{\text {b }}<0.05$ significant difference with control group; GLC after: ${ }^{\text {a }}<0.05$ significant difference with control and treatment groups; Urea: ${ }^{\text {a }}<0.05$ significant difference with control and treatment groups; B.W: Body Weight GLC: Glucose 
The statistical study of the mean serum levels of urea and creatinine showed no significant difference in serum concentration of creatinine among different groups $(\mathrm{p}>0.05)$. However, there is a significant difference in the mean serum concentration urea between the control and the diabetic groups. Also, a significant difference was noticed between the treatment group and the diabetic and control groups $(\mathrm{p}<0.05)$.
In addition, a significant difference was seen in serum concentration of liver enzyme AST in the control group compared to the diabetic group $(p<0.05)$. In this regard, there was no significant difference between the control group and the treatment group $(p>0.05)$. Moreover, the study of the results showed no significant difference in the mean serum concentration of ALT among the different study groups $(\mathrm{p}>0.05)$.

Table 2. Mean of serum concentration of lipid and lipoproteins and liver enzymes activity in studied group's. The values represent the mean \pm SE for ten rats per group

\begin{tabular}{llllll}
\hline Parameter & Control & Diabetic & Treatment & F & P value \\
\hline TG (mg/dl) & $57 \pm 4.9464 \mathrm{~b}$ & $89.25 \pm 3.7272 \mathrm{a}$ & $68.57 \pm 6.0219 \mathrm{ab}$ & 3.89 & 0.05 \\
Ch (mg/dl) & $54 \pm 3.5637 \mathrm{c}$ & $79 \pm 2.1602 \mathrm{a}$ & $66.71 \pm 2.1191 \mathrm{~b}$ & 9.11 & 0.004 \\
LDL(mg/dl) & $20.40 \pm 2.0052 \mathrm{~b}$ & $32.02 \pm 1.2410 \mathrm{a}$ & $28.50 \pm 1.0041 \mathrm{a}$ & 7.64 & 0.007 \\
HDL (mg/dl) & $23.50 \pm 0.4082 \mathrm{a}$ & $17.25 \pm 0.5400 \mathrm{~b}$ & $19.64 \pm 0.7456 \mathrm{~b}$ & 10.20 & 0.003 \\
VLDL (mg/dl) & $13.05 \pm 1.1646 \mathrm{~b}$ & $20.36 \pm 1.3117 \mathrm{a}$ & $16.67 \pm 1.0911 \mathrm{ab}$ & 3.91 & 0.049 \\
ALT (U/L) & $137.50 \pm 8.1098 \mathrm{a}$ & $198.25 \pm 12.5896 \mathrm{a}$ & $162.85 \pm 9.2871 \mathrm{a}$ & 3.76 & 0.054 \\
AST (U/L) & $203 \pm 9.3276 \mathrm{~b}$ & $303.25 \pm 6.4982 \mathrm{a}$ & $232 \pm 4.9532 \mathrm{~b}$ & 24.41 & 0.000 \\
\hline
\end{tabular}

Different letters in each row indicate a significant difference between groups. Significance level was considered as $\mathrm{P}<0.05$. TG: ${ }^{a} \mathrm{P}<0.05$ significant difference with control group; $\mathrm{Ch}:{ }^{a} \mathrm{P}<0.05$ significant difference with control and treatment groups; LDL: ${ }^{a} \mathrm{P}<0.05$ significant difference with control group; HDL: ${ }^{\mathrm{P}}<0.05$ significant difference with diabetic and treatment groups; VLDL: ${ }^{a} \mathrm{P}<0.05$ significant difference with control group; AST: ${ }^{a}<0.05$ significant difference with control and treatment groups; TG: Triglyceride; Ch: cholesterol; LDL: Low-density lipoprotein; HDL: High-density lipoprotein; VLDL: Very low-density lipoprotein; ALT: alanine aminotransferase; AST: Aspartate aminotransferase

\section{HbA1c}

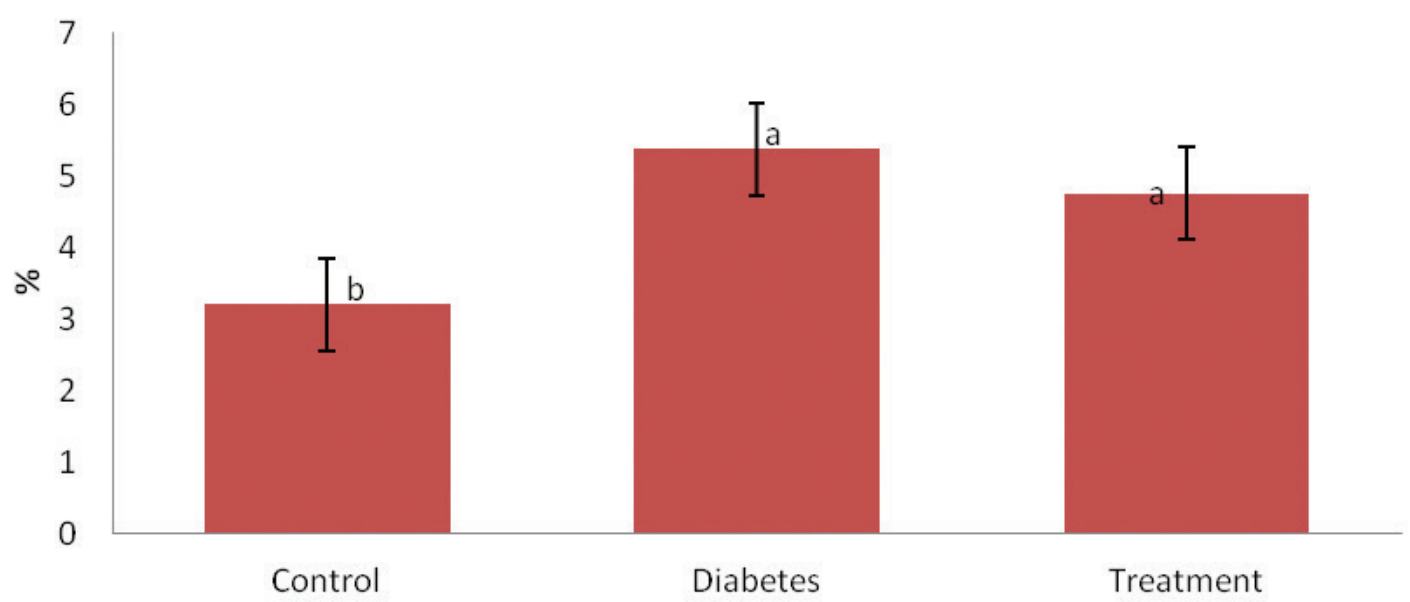

Figure 1. Effect of oleuropein on hemoglobin $\mathrm{A}_{1} \mathrm{C}$ in studied groups. Different letters in each column indicate a significant difference between groups. Significance level was considered as $\mathrm{P}<0.05$. ${ }^{\mathrm{a}} \mathrm{P}<0.05$ significant difference with control group 


\section{$\log (\mathrm{TG} / \mathrm{HDL})$}

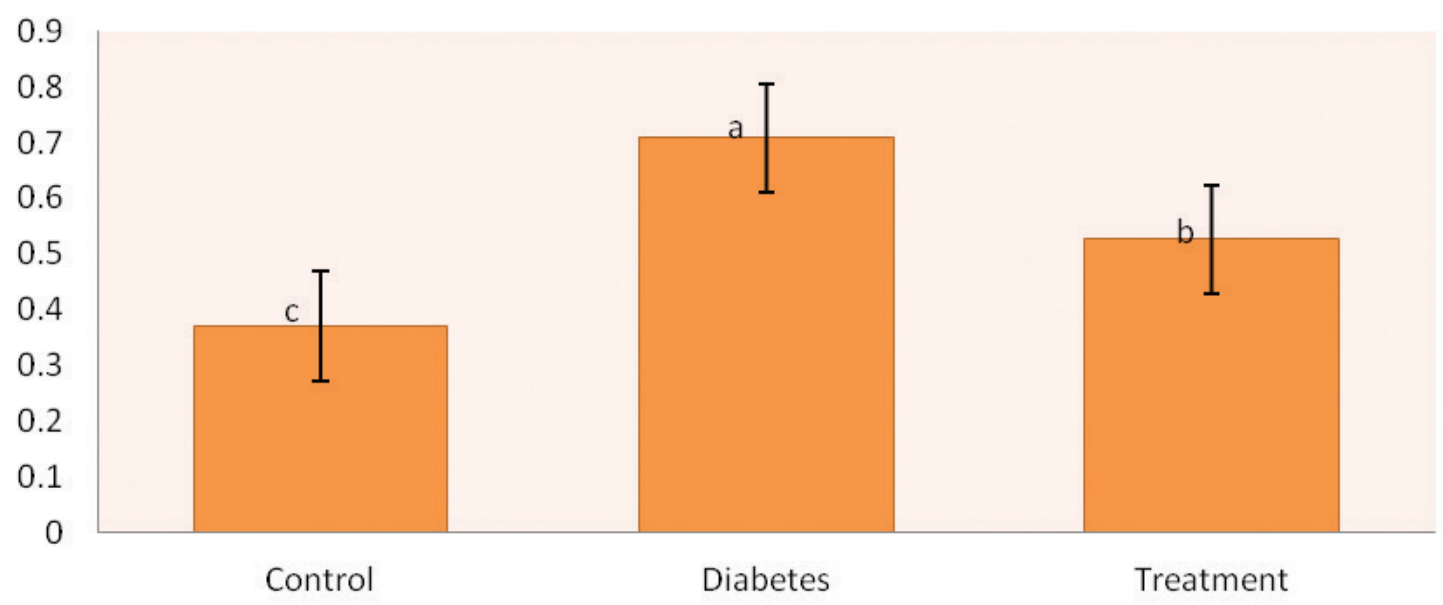

Figure 2. Effect of oleuropein on atherogenic index in studied groups. Different letters in each column indicate a significant difference between groups. Significance level was considered as $\mathrm{P}<0.05{ }^{\mathrm{a}} \mathrm{P}<0.05$ significant difference with control and treatment groups

\section{DISCUSSION}

Diabetes type I is a disease related to oxidative stress. Various differences have been reported in terms of formation of free radicals including nephropathy, retinopathy, cardiovascular, and metabolism disorders. In addition, it seems that hyperglycemia is accompanied by an increase in free radicals in the body. Furthermore, food antioxidants are effective in reducing the complex effects resulting from oxidative stress of diabetes type I (20). Chronic hyperglycemia induces carbonyl stress, which in turn increases lipid peroxidation. Elevated lipid peroxidation causes oxidative damage by increasing peroxyl and hydroxyl radicals (21).

The results of this study showed that diabetes significantly increased serum glucose compared to the control group. It is known that streptozotocin, by destruction of beta cells, can increase the blood glucose level. These results are consistent with previous research $(22,23)$. Whereas, treatment of diabetic animals with oleuropein significantly decreased serum glucose level in the treatment group. The hypoglycemic effect of oleuropein may be due to the increased secretion of insulin from beta cells. This finding is consistent with the results of previous studies $(23,24)$.
The results of the present study showed a significant weight drop in animals in the diabetic group compared to that of the control group. The weight drop in the diabetic animals compared to that in the control group can be attributed to the extreme breakdown of tissue proteins (23). Moreover, it was identified that oleuropein could prevent weight loss. There is no significant difference between the treatment group and the control group. Hence, the decrease in muscle decomposition may be due to the control of blood glucose. These findings are in agreement with the study conducted by Gandi and Sasikumar (23). The results of the present research showed that diabetes causes a significant increase in triglyceride, cholesterol, LDL, and VLDL serum compared to the control group. In comparison, the treatment of diabetic animals with oleuropein for 30 days caused a significant decrease in the serum concentration of cholesterol compared to the diabetic group. In the diabetic group, the serum concentration of HDL was significantly decreased compared to that of the control group. Ahmadvand et al. showed that oleuropein could reduce the risk of cardiovascular mortality by improving factors such as lipid profile and atherosclerosis index in patients suffering from nephrotoxicity. The researchers have reported that oleuropein derived from olive's leaves and oil has a high antioxidant activity and 
is able to prevent nephrotoxicity's side effects including hyperlipidemia. Also, a previous study by Ahmadvand et al. shows the protective effects of oleuropein on oxidative stress resulting from spinal cord injury $(16,19)$. The results of the present study are not consistent with those of Ahmadvand et al. (16). This difference in some results may be due to a shorter treatment period in our study or the method of oleuropein administration; or both.

Several studies have reported the antioxidant effects of oleuropein. Nekouian et al. reported that oleuropein has a heart protective effect that partly results from its antioxidant activity (18). In diabetes disease, antioxidants and activity of antioxidant enzymes are decreased with an increase in products of lipid oxidation (16). Moreover, the increased nonenzymatic glycosylation followed by hyperglycemia may be a potential reason for cardiovascular complications in diabetes disease (25). Also, the results of this research demonstrate that the serum concentration of liver enzyme AST significantly increased in the diabetic group compared to the control and treatment groups. However, the study of the results showed no significant difference in the mean serum concentration of ALT among different studied groups. This difference in results of AST and ALT may be due to higher concentration of AST in the hepatic acinus, and damage to this area, whether ischemic or toxic, may result in greater alteration to AST levels (26). This increase in the serum levels of liver enzymes can be the result of liver toxicity and necrosis of hepatocytes caused by oxidative stress (27). In addition, it was noticed that the treatment of diabetic animals with oral oleuropein caused a significant decrease in AST enzyme in the treatment group compared to the diabetic group.

Furthermore, there is no significant difference between the control and the treatment group, suggesting that atherosclerosis index in treatment group significantly decreased compared to that of the diabetic group. This result can be attributed to the anti-oxidative and antihyperlipidemic effects of the oleuropein. Meanwhile, the oleuropein was not able to significantly reduce $\mathrm{Hb} \mathrm{AlC}$ levels in the treatment group.

$\mathrm{Hb} \mathrm{A} 1 \mathrm{C}$ was increased in a diabetic patient and the glycation rate was proportional to the hyperglycemia status. It has been documented that glycation induces the formation of free radicals derived from oxygen. Therefore, $\mathrm{Hb}$ A1C levels are described as an indicator of the degree of oxidative stress in diabetes. Therefore, measuring $\mathrm{Hb} \mathrm{A} 1 \mathrm{C}$ is a very sensitive indicator of glycemic control (21).
Besides, the results showed that the serum concentration of urea in the diabetic group was significantly increased compared to that of the control group. The increased production of urea in diabetic animals can be attributed to the increased catabolism of plasma and liver proteins (24).

\section{CONCLUSION}

In summary, the results of this research indicate the useful effects of oleuropein on hyperglycemia, glucose metabolism, lipid, and sclerosis in diabetic animals with atherosclerosis. Therefore, oleuropein can be introduced as an antisclerosis compound that is able to reduce the risk of cardiovascular disease in diabetic patients. However, further studies are needed to identify the mechanism of its effect.

\section{CONFLICT OF INTEREST STATEMENT}

The authors declared that they have no potential conflict of interest with respect to the authorship and/or publication of this article.

\section{ACKNOWLEDGMENT}

The results reported in this paper are from the thesis of Sina Amirnahavandi, who was supported by the Islamic Azad University, Tabriz, Iran.

\section{REFERENCES}

1. Risbridger, G., Wang, H., Young, P., Kurti, T., Wang, Y.Z., Lubahn, D. et al. (2001). Evidences that epithelial and mesenchymal estrogen receptor alpha mediates effects of estrogen on prostatic epithelium. Dev Biol. 229, 157-166.

https://doi.org/10.1006/dbio.2000.9994

PMid:11150243

2. Baynes, J., Thorpe, S. (1999). Role of oxidative stress in diabetic complications: a new perspective on an old paradigm. Diabetes 48, 1 - 9 .

https://doi.org/10.2337/diabetes.48.1.1

PMid:9892215

3. Ullah, A., Khan, A., Khan, I. (2016). Diabetes mellitus and oxidative stress-A concise review. Saudi Pharmaceutical Journal 24(5): 547-553.

https://doi.org/10.1016/j.jsps.2015.03.013

PMid:27752226 PMCid:PMC5059829 
4. Meyer, K., Deutscher, J., Anil, M., Berthold, A., Bartsch, G., Kiess, W. (2000). Serum androgen levels in adolescents with type I diabetes: relationship to pubertal stage and metabolic control. J Endocrinol Invest. 23, 362-368.

https://doi.org/10.1007/BF03343739

PMid:10908163

5. Keith, K.G., Fonseca, V., Tan, M.H., Dalpiaz, A. (2001). Narrative review: Hepatobiliary disease in type 2 diabetes mellitus. Ann. Intern. Med. 141(12): 946-956.

6. Kanter, M., Coskun, O., Korkmaz, A., Oter, S. (2004). Effects of Nigella sativa on oxidative stress and $\beta$ cell Damage in streptozotocin - induced Diabetic rats. Anat Rec A. 279A: 685-691.

https://doi.org/10.1002/ar.a.20056

PMid:15224410

7. Kumar, S., Malhotra, R., Kumar, D. (2010). Antidiabetic and free radical scavenging potential of euphorbia hirta flower extract. Indian J. Pharm. Sci. 72(4): 533-537.

https://doi.org/10.4103/0250-474X.73921

PMid:21218075 PMCid:PMC3013561

8. Al-Jameil, N., Khan, F. A., Arjumand, S., Khan, M. F., Tabassum, H. (2014). Associated liver enzymes with hyperlipidemia profile in type 2 diabetes patients. Int J Clin Exp Pathol. 7(7): 4345-4349. PMid:25120819 PMCid:PMC4129054

9. Anup, K.M., Smriti, T., Zabeer, A., Ram, K.S. (2012). Antidiabetic and antihhyperlipidemic effect of Euphorbia hirta in streptozotocin induced diabetic rats. Scholars Research Library 4 (2): 703-707.

10. Morrison, J., Dhanasekaran, S., Sheen, R., Frampton, C., Mensah-Brown, E. (2006). The effect of streptozotocin-induced diabetes on the rat seminal vesicle : A possible pathophysiological basis for disorders of ejaculation. Ann. N. Y. Acad. Sci. 1084, 267-279.

https://doi.org/10.1196/annals.1372.013

PMid:17151307

11. Aljamal, A., Ibrahim, A., Al-Fararjeh, M.A., Alqadi, T. (2012). Effects of rosemary on lipid profile in diabetic rats. Afr J Biochem Res. 6 (7): 222-225.

12. Shukla, R., Sharma, S B., Puri, D., Pabhu, K. M., Murthy, P.S. (2006). .Medicinal plants for treatment of diabetes mellitus. Indian J Clin Biochem. 15, 169-177.

13. Olmez, E., Vural, K., Gok, S., Ozturk, Z., Kayalar, H., Ayhan, S., et al. (2015). Olive leaf extractimproves the atherogenic lipid profile in rats fed a high cholesterol diet. Phytother Res. 29(10): 1652-1616.

https://doi.org/10.1002/ptr.5445

PMid:26328503
14. Alirezaei, M., Dezfoulian, O., Kheradmand, A., Neamati, Sh., Khonsari, A., Pirzadeh, A. (2012). Hepatoprotective effects of purified oleuropein from olive leaf extract against ethanol-induced damages in the rat. Iranian Journal of Veterinary Research. 13(3): 40.

15. Al Jamal, A., Ibrahim, A. (2011). Effects of olive oil on lipid profiles and blood glucose in type2 diabetic patients. Intentional Journal Diabetes \& Metabolism 19, 19-22.

16. Ahmadvand, H., Noori, A., Ghasemi Dehnoo, M., Bagheri, S., Cheraghi, R. (2014). Hypoglycemic, hypolipidemic and antiatherogenic effects of oleuropein in alloxan-induced Type 1 diabetic rats. Asian Pac J Trop Dis. (Suppl 1): S421-S425. https://doi.org/10.1016/S2222-1808(14)60481-3

17. Sangi, S. M. A., Ibrahim, S. M., Fawzy, A. M., Elsamoual, I. A. E., Shaker, A. S. (2015). Antihyperglycemic effect of thymoquinone and oleuropein, on streptozotocin-induced diabetes mellitus in experimental animals. Pharmacogn Mag. 11(2): S251-S257.

https://doi.org/10.4103/0973-1296.166017

PMid:26664013 PMCid:PMC4653335

18. Nekooeian, A. A., Khalili, A., Khosravi, M. B. (2014). Oleuropein offers cardioprotection in rats with simultaneous type 2 diabetes and renal hypertension. Indian J. Pharmacol. 46(4): 398-403. https://doi.org/10.4103/0253-7613.135951 PMid:25097277 PMCid:PMC4118532

19. Ahmadvand, H., Bagheri, S., Tamjidi-Poor, A., Cheraghi, M., Azadpour, M., Ezatpour, B., et al. (2016). Biochemical effects of oleuropein in gentamicin-induced nephrotoxicity in rats. ARYA Atheroscler. 12(2): 87-93.

PMid:27429628 PMCid:PMC4933747

20. Qadir, N. M ., Ali, K. A., Qader, S. W. (2016). Antidiabetic effect of oleuropein from olea europaea leaf against alloxan induced type 1 diabetic in rats. Braz. Arch. Biol. Technol. v.59: e16150116. https://doi.org/10.1590/1678-4324-2016150116

21. Nakhaee, A., Bokaeian, M., Saravani, M., Farhangi, A., Akbarzadeh, A. (2009). Attenuation of oxidative stress in streptozotocin-induced diabetic rats by Eucalyptus Globulus. Indian J Clin Biochem. 24 (4): 419-425.

https://doi.org/10.1007/s12291-009-0075-1

PMid:23105871 PMCid:PMC3453050

22. Ramakrishna, V., Jailkhani, R. (2007). Evaluation of oxidative stress in insulin dependent diabetes mellitus (IDDM) patients. Diagn Pathol. 2, 22. https://doi.org/10.1186/1746-1596-2-22 PMid:17603912 PMCid:PMC1936413 
23. Gandhi, G. R., Sasikumar, P. (2012). Antidiabetic effect of Merremia emarginated Burm. F. in streptozotocin induced diabetic rats. Asian Pac J Trop Biomed. 2(4): 281-286.

https://doi.org/10.1016/S2221-1691(12)60023-9

24. Pareek, H., Sharma, S., Khadija, B.S., Jain, K., Jain, GC. (2009). Evaluation of hypoglycemic and anti-hyperglycemic potential of Tridax procumbent (Linn.). BMC Complement Altern Med. 9, 48.

https://doi.org/10.1186/1472-6882-9-48

PMid:19943967 PMCid:PMC2790435

25. Kondeti, V. K., Badri, K. R., Maddirala, D. R., Thur, S. K. M., Fatima, S. S., Kasetti, R.B., et al. (2010). Effect of Pterocarpus santalinus bark, on blood glucose, serum lipids, and plasma insulin and hepatic carbohydrate metabolic enzymes in streptozotocin induced diabetic rats. Food Chem Toxicol. 48, 1281-1287.

https://doi.org/10.1016/j.fct.2010.02.023

PMid:20178824
26. Giannini, E.G., Roberto Testa, R., Savarino, V. (2005). Liver enzyme alteration: a guide for clinicians. CMAJ. 172(3): 367-379.

https://doi.org/10.1503/cmaj.1040752

PMid:15684121 PMCid:PMC545762

27. Hassan, H. A., El-Agmy, S. M., Gaur, R. L., Fernando, A., Raj, M. H. G., Outhit, A. (2009). In vivo evidence of hepato and reno-protective effects of garlic oil against sodium nitrite-induced oxidative stress. Int J Biol Sci. 5, 249-255.

https://doi.org/10.7150/ijbs.5.249

PMid:19305642 PMCid:PMC2659008

Please cite this article as: Amirnahavandirahbar S., Nasirzadeh M.R. Biochemical effects of oleuropein in streptozotocin induced diabetic male rat. Mac Vet Rev 2018; 41 (2): 187-194. https://doi.org/10.2478/macvetrev-2018-0021 